\title{
A Self-Evaluation Tool for Quantitative User Research within the digital.me Project
}

\author{
Andreas Schuller ${ }^{1}$, Rafael Giménez ${ }^{2}$, and Fabian Hermann ${ }^{1}$ \\ ${ }^{1}$ Fraunhofer-Institute for Industrial Engineering, Stuttgart, Germany \\ \{andreas.schuller, Fabian.Hermann\}@iao.fraunhofer. de \\ ${ }^{2}$ Barcelona Digital Centre Tecnològic, Barcelona, Spain \\ rgimenez@bdigital.org
}

\begin{abstract}
For upcoming validations within the di.me project, the technical evaluation components will be an important instrument for monitoring overall key usage indicators and serve as the basis for the further analysis of usage data. Consolidated findings acquired from the evaluation components shall serve as the basis for further improvements on the developed clients and overall di.me system. This paper states a list of related requirements as well as a technical overview of the employed system.
\end{abstract}

Keywords: Quantitative user research, Self-Evaluation, User Feedback, User Research, Usability, User Experience, Requirements.

\section{Introduction}

The self-evaluation system as described here is targeted to enable the gathering of relevant client usage data for upcoming validations within the project. In particular, this shall address validations that might involve larger usage numbers and a setting, which cannot be directly controlled by any of the project partners. The acquired data will serve as the basis for evaluation and the measurement of key indicators regarding usability and user experience. There are two di.me clients developed, a web application and an Android application for mobile devices. Both clients are supported by the Self-Evaluation Tool.

For the Self-Evaluation Tool (SET), a number of requirements have been collected. Since the di.me software is especially concerned with safeguarding the user's privacy and personal data, there have been special considerations for related functions. All gathered requirements are listed in section two "System Requirements Analysis".

As stated in for the project MyExperience, Fröhlich et al. [1] mention two important factors of such a Self-Evaluation Tool, which are also central for the system employed in di.me:

1. Implicit logging of device usage, user context and environment context.

2. Explicit questionnaires to collect subjective user feedback in the particular situation. 
For the shown di.me system, the decision has been made to also divide these two aspects on a technical level. Implicit interaction is using the existing di.me architecture to gather this data on a customized di.me Evaluation Server Service; explicit data acquisition is employing an existing open source application. A detailed description is given in section three "Overview of the employed system".

\subsection{Considerations of Related Tools}

For the gathering of implicit user data, there are some frameworks and established software solutions on the market that were considered. A well-known analysis tool is offered by Google Analytics [2]. There exist versions for analyzing both web sites and mobile Android applications. However, the usage of Google Analytics servers would not be suited for the di.me project's decentralized server architecture. Mozilla offers its own test suite, Mozilla Test Lab Test Pilot [3] where users can get involved in testing future versions of a browser. The Mozilla Test Lab is strongly related to Mozilla's related projects and does not support usage by external projects. Another similar project is the open source project Piwic [4], which offers steadily growing features, but does not support native Android applications at the moment.

\section{System Requirements Analysis}

Derived from the aforementioned main objectives of the evaluation tool, the following table illustrates several derived requirements. The right column illustrates how these requirements are met by the developed technical solution.

Table 1. General requirements table

\begin{tabular}{||l|l||}
\hline REQUIREMENT & DEVELOPMENT PROTOTYPE \\
\hline $\begin{array}{l}\text { Allowing participating di.me users to } \\
\text { send interaction data and system status } \\
\text { information for evaluation purposes to a } \\
\text { consortium Evaluation Server on a vol- } \\
\text { untary basis. }\end{array}$ & $\begin{array}{l}\text { The amount of usage data sent can be set } \\
\text { up ins, the raw data sent contains different } \\
\text { sets of user and interaction data } \\
\text { (see table 2 for details). }\end{array}$ \\
\hline $\begin{array}{l}\text { Presenting participating di.me users } \\
\text { short questionnaires or single questions } \\
\text { in particular use situations (like e.g. first } \\
\text { system use, closing of the system, use of } \\
\text { interesting functionality, at particular } \\
\text { time points). }\end{array}$ & $\begin{array}{l}\text { Online questionnaires can be filled out } \\
\text { by the user at all times, independently by } \\
\text { the moment this does not allow for au- } \\
\text { the mated triggering of questionnaires, } \\
\text { tomang } \\
\text { special user groups can be addressed } \\
\text { explicitly through the di.me central web- } \\
\text { portal during beta tests. } \\
\text { The possibility of automating the alloca- } \\
\text { tion of questionnaires according to user } \\
\text { behavior is planned for future releases. }\end{array}$ \\
\hline
\end{tabular}


Table 1. (continued)

\begin{tabular}{||l|l||}
\hline $\begin{array}{l}\text { Allowing participating di.me users to } \\
\text { send their feedback on the di.me system, }\end{array}$ & $\begin{array}{l}\text { The developed di.me portal and commu- } \\
\text { nity websites will allow for a general } \\
\text { nse situations. }\end{array}$ \\
\hline
\end{tabular}

Additionally, for the technical development of the SET functionality, these key decisions have been taken:

- Usage data will be sent along with REST calls to the Personal Server (PS): this means that the interaction recording functionalities will rely on the same communication protocol as for the transmission of other data.

- All data reaching the Evaluation Server will have to pass the security infrastructure of the PS. If this is enabled by the user, this data is being sent in intervals to an Evaluation Server.

- The data will be anonymized by the Personal Server or contain no personally traceable data: Since all usage data has to pass the $P S$, it will be justified that the data is anonymized and obfuscated there. Therefore the Evaluation Server has no possibility to analyze mass clear user data.

- Evaluation questionnaires will be conducted online, through an external tool: since there are a multitude of questionnaire systems available, the decision had been taken to employ an existing open source tool for this purpose.

\subsection{Data Privacy Levels}

The following sections will give an impression, in which ways the usage of the SET can be utilized for evaluating the developed di.me system prototypes. The following table gives an overview of relevant usage data, a potential privacy classification, and

Table 2. Distinction of interaction data by privacy levels

\begin{tabular}{|c|c|c|}
\hline $\begin{array}{l}\text { PRIVACY } \\
\text { LEVEL }\end{array}$ & INTERACTION DATA & ANALYZED INDICATORS \\
\hline $\begin{array}{l}\text { no or little } \\
\text { concerns }\end{array}$ & $\begin{array}{l}\text { - Timestamp of transaction } \\
\text { - Reference to current client } \\
\text { type (mobile or desktop) } \\
\text { - Reference to current View on } \\
\text { the UI (encoded) } \\
\text { - Reference to concrete action } \\
\text { taken on the UI (encoded) } \\
\text { - Reference to particular call } \\
\text { made (e.g. new group or } \\
\text { changed existing group) with- } \\
\text { out any content }\end{array}$ & $\begin{array}{l}\text { - Average Time to follow } \\
\text { interaction sequences (e.g. } \\
\text { setting up group, adding dif- } \\
\text { ferent users) } \\
\text { - Average number of interac- } \\
\text { tion steps for conducting } \\
\text { certain functions } \\
\text { - Preferred ways of interac- } \\
\text { tion (if there are more than } \\
\text { one) }\end{array}$ \\
\hline
\end{tabular}


Table 2. (continued)

\begin{tabular}{|c|c|c|}
\hline $\begin{array}{l}\text { More detailed } \\
\text { usage data but } \\
\text { anonymized, } \\
\text { not directly } \\
\text { traceable }\end{array}$ & $\begin{array}{l}\text { - Reference to current client } \\
\text { type and machine (e.g. Phone } \\
\text { Version, Browser type) } \\
\text { - Reference to situational or } \\
\text { contextual data (current place, } \\
\text { current situation encoded) } \\
\text { - Encoded Identifier of current } \\
\text { user without any clear infor- } \\
\text { mation (to distinguish the } \\
\text { same user) } \\
\text { - Obfuscated payload of trans- } \\
\text { mitted REST-call } \\
\text { - Generally personal, but not } \\
\text { directly identifiable informa- } \\
\text { tion (e.g. Gender, Birthday) }\end{array}$ & $\begin{array}{l}\text { - Average number of different } \\
\text { objects per type (e.g. aver- } \\
\text { age number of groups) } \\
\text { - Statistics about technology } \\
\text { used } \\
\text { - user groups (e.g. old - } \\
\text { young, male - female) } \\
\text { - Different general behaviours } \\
\text { according to different situa- } \\
\text { tions or places } \\
\text { - Detection of covariance } \\
\text { between situations and } \\
\text { actions taken } \\
\text { - Detection of longer se- } \\
\text { quences of actions taken } \\
\text { (long-term usage, cycles of } \\
\text { usage intensiveness, etc.) } \\
\text { - Detection of similarities } \\
\text { between users at certain } \\
\text { events }\end{array}$ \\
\hline $\begin{array}{l}\text { Personally } \\
\text { traceable data, } \\
\text { potential pri- } \\
\text { vacy concerns }\end{array}$ & $\begin{array}{l}\text { - Identifier of the user linked } \\
\text { with clear identification in- } \\
\text { formation (e.g. Name or Nick- } \\
\text { name) } \\
\text { - Reference to concrete situa- } \\
\text { tions and places } \\
\text { - Plain text payload of transmit- } \\
\text { ted REST-call }\end{array}$ & $\begin{array}{l}\text { - Reconstruction of move- } \\
\text { ment profiles at events } \\
\text { - Reconstruction of time pro- } \\
\text { files of individual users } \\
\text { - Linking between different } \\
\text { contacts, deducing knowl- } \\
\text { edge from concrete personal } \\
\text { networks }\end{array}$ \\
\hline
\end{tabular}

examples of possible relevant higher level indicators that could be deduced from the raw data. The di.me SET only collects data from the first and second privacy levels where there is no directly traceable data involved. Furthermore, approval has to be given by the user for both levels explicitly as opt-in.

\section{Overview of the Employed System}

Relevant software parts of the SET-components are within the di.me clients and in the di.me (service) gateway, which includes a service adapter particularly for the Evaluation Server. On the client, user interaction data is being tracked if the functionality is enabled by the user. Further settings for information tracking can be adjusted. 
The transmitted data is stored within the Personal Servers temporarily, and then sent anonymously to the Evaluation Server in fixed time intervals. The Evaluation Server is able to permanently store data from multiple Personal Servers. For a more thorough overview of the complete di.me system, see [7].

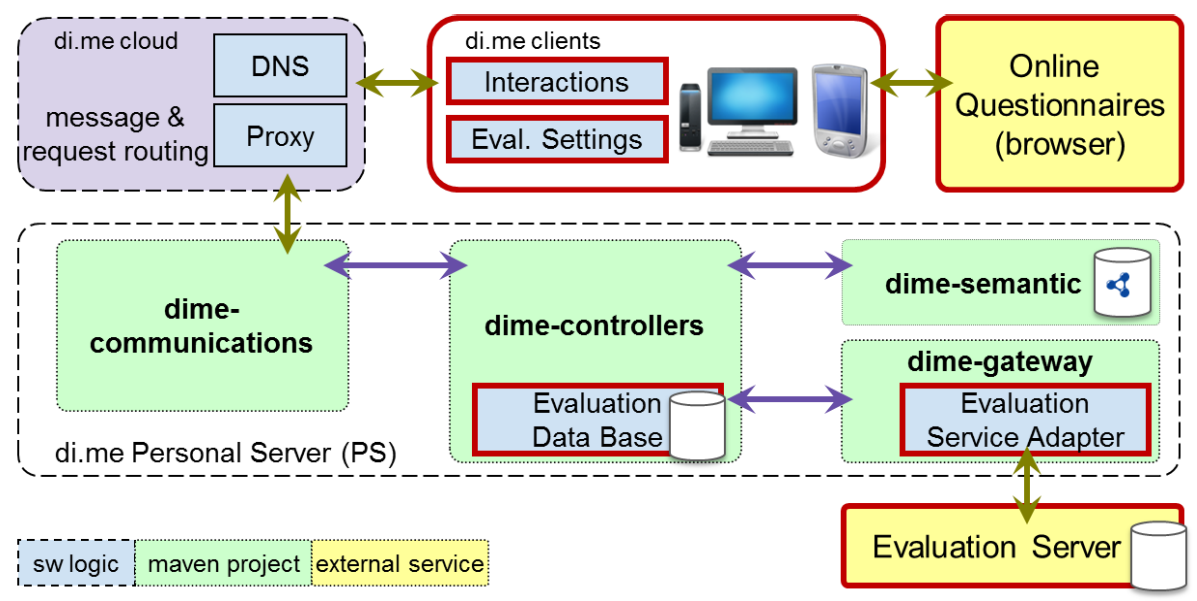

Fig. 1. Relevant components in the di.me system architecture for the SET are marked with a thick border (red)

Online questionnaires are stored on a different external sever, running the open source implementation of Limesurvey [5]. These questionnaires are accessed through the client's browsers directly and not through the PS. The data transmitted through the online questionnaires (which is of course voluntary and where only provided answers are sent) is completely separated from the tracking data, and therefore direct linking between these two data sets is being avoided.

Since the direct proposal of questionnaires towards the user is covered externally through the respective browser on the client platform, the functional documentation describes the set up and communication of the interaction tracking of the users.

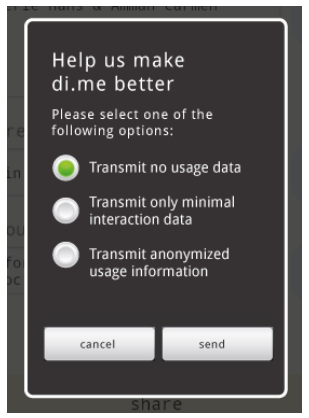

Fig. 2. Early concept screenshot of the mobile user interface showing different options for the transmission of interaction usage data 


\subsection{Communication through the di.me REST-API}

Evaluation calls are routed through the REST-API interface, following the technical documentation. The decision had been taken to introduce this as a separate call for this (in contrast to providing additional evaluation information with each REST-call), in order to keep the communication flexible and independent of future changes of the API. The payload is using the same standard envelope for the transmission of the data, as most of the other sent objects. For readability purposes, the standard payload envelope is omitted in the following example:

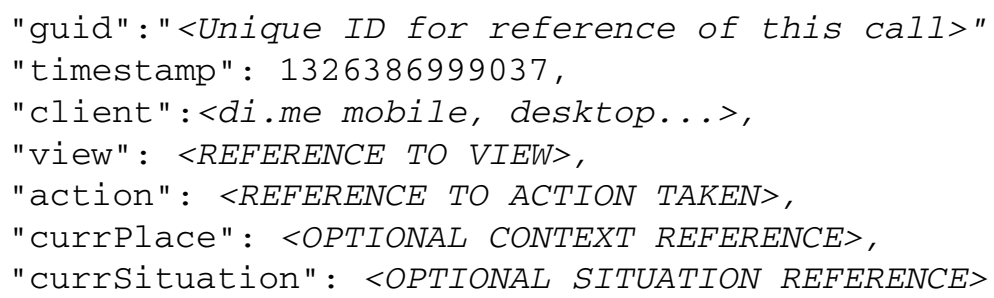

The client points to the type of di.me client that was used. View and action references are described in the following section. The References to current context information (currPlace and currSituation) are optional, according to the user settings.

\subsection{Encoding of Views and Actions}

For the storing different views and the according actions, an encoding scheme has been set up. The following image contains a showcase example of the general structure of the encoding for the mobile client. References are named according to their position within the information architecture. The naming convention takes into account the initially chosen element (e.g. people) and also the activated tab (e.g. people.groups and people.all).

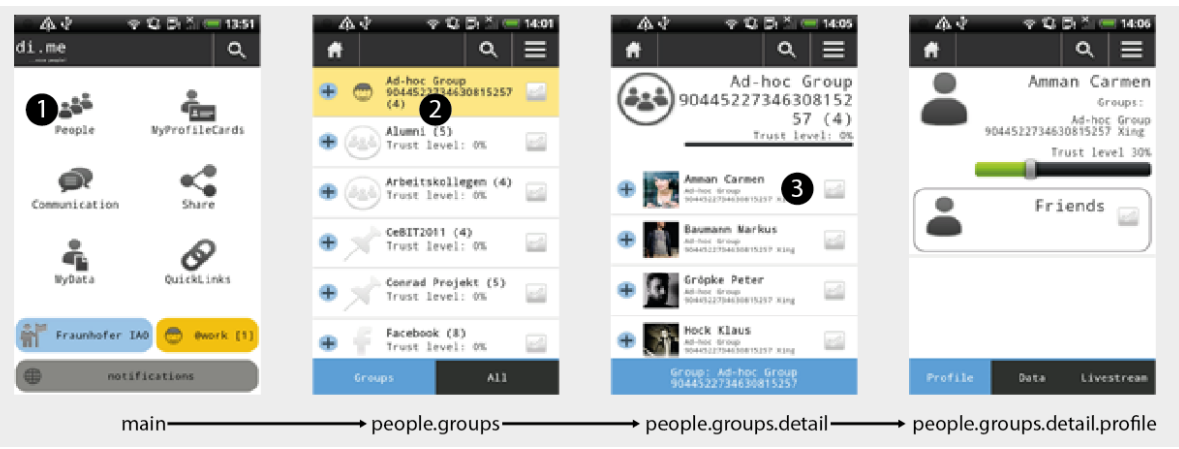

Fig. 3. Example drill down through different view hierarchies on the mobile client, numbers indicate the clicked or touched areas 
For the general encoding of different view areas, the descriptive string is following the actual structure within the UI. Examples of referencing views according to the scheme would be:

- people.groups.detail (the detail view of the selected group)

- data.databox.detail.resource (an individual resource of a particular databox or folder)

The coding scheme resembles a kind of navigation breadcrumb as would be used in web sites. All references are strongly related to the class or package identifiers used in the client's code. Therefore, the identifiers between mobile and web-UI can differ slightly.

The references of the functions executed by the user can take on a related name to the caption within the UI (e.g. "new", "add", "delete") and can be the same for a number of screens. Using this naming scheme, the combination of client reference with view and action reference are unique for each chosen UI-function. This way, user preferences for alternative ways of executing the same function can be detected.

\subsection{Tracking Explicit User Feedback}

Limesurvey is an online evaluation tool and server, which provides the possibility to create and configure online questionnaires and users to register and complete online surveys. It offers a rich set of options and configurations for editing and setting up questionnaires (e.g. different question types, multi-language support, and unlimited number of participants). The tool has been used in many previous studies within scientific and industry-related projects.

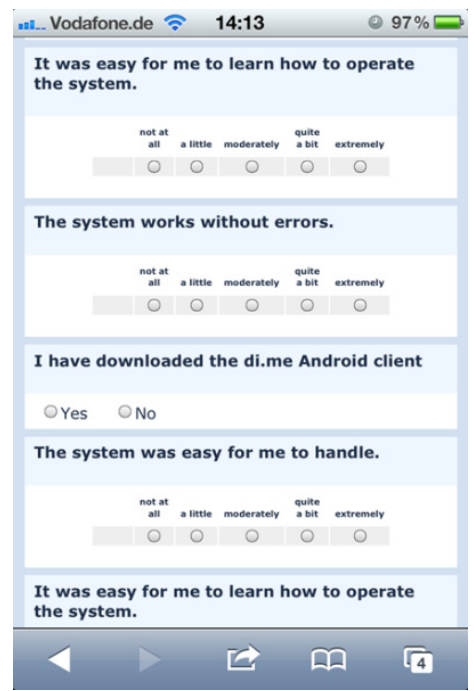

Fig. 4. Screenshot of a test questionnaire on a mobile setup 


\section{Rationale for Using Limesurvey}

Apart from previous experiences of using the Limesurvey tool, there are certain particular characteristics that speak for the application within this scope of the di.me project because it meets the associated requirements:

- Both the web-application and the hosting server are under an open source license. A server can be easily set up for this purpose by the project partners. No other unauthorized party has access to this server.

- Anonymized questionnaires: Questionnaires can be set up without storing any personally identifiable information from the users (unless users provide this information by themselves).

- A multitude of different question types are pre-set within the application.

- Stylesheets can be employed to include a certain look and feel to adapt to the other user interfaces. Increasing mobile support.

For the usage in the di.me project, Limesurvey seems as optimal option regarding open source solutions, and servers allowing for self-hosting. This way, the data flows can still be controlled and matched within the overall di.me system, and the project can benefit from the various features already implemented and offered.

\section{Conclusion}

Within this paper it was tried to show some of the essential requirements, fundamentals and an initial technical overview of some aspects of the implemented SET in the di.me project

Although no real usage data could be acquired with the SET yet, first implementations and prototypical test runs have yielded to first promising results. As for the planned di.me validations and beta tests, the first aim is to robustly collect the most general information, and iteratively include more sophisticated usage data later on. Further publications on the analyzed usage data and derived conclusions for the di.me system and possible improvements of the SET, are planned.

As described by Sellner [6] there is the possibility to expand the Self-Evaluation Tool suite by (mobile) widgets, and to increase the technical support of the SET to other user research methods (like a usage diary with possibilities to include rich media like videos). Also, the automated triggering of particular questionnaires according to different interactions or user groups is currently being evaluated. With the inclusion of these additional aspects and further improvements, the SET will allow for more and more autonomous and sophisticated analysis of usage data in diverse application areas.

Acknowledgments. This work is funded by the European Commission under the Seventh Framework Program FP7/2007-2013 (digital.me - ICT-257787). 


\section{References}

1. Fröhlich, J., et al.: MyExperience: a system for in situ tracing and capturing of user feedback on mobile phones. In: Proceedings of the 5th International Conference on Mobile Systems, Applications and Services (MobiSys 2007). ACM, New York (2007)

2. Google, Google Analytics, https: / / developers.google.com/analytics/

3. Mozilla Labs, Mozilla Test Pilot, https://testpilot.mozillalabs.com/

4. Piwic Project Team, Piwic Open Source Web Analytics, http://piwik.org/

5. LimeSurvey Project Team, Carsten Schmitz: LimeSurvey: An Open Source survey tool LimeSurvey Project Hamburg, Germany (2013), http : / / www . limesurvey . org

6. Sellner, T.: Konzeption und prototypische Entwicklung eines kontextbezogenen Evaluierungssystems für mobile Anwendungen. Master-Thesis Fakultät Informatik Studiengang Medien- und Kommunikationsinformatik Hochschule Reutlingen (2011)

7. Thiel, S., et al.: A Requirements-Driven Approach Towards Decentralized Social Networks. In: Park, J.J.(J.H.), Leung, V.C.M., Wang, C.-L., Shon, T. (eds.) Future Information Technology, Application, and Service. LNEE, vol. 164, pp. 709-718. Springer, Netherlands (2012) 